\title{
Nietzsche e a orientação perfeccionista de sua tentativa de estimar valores
}

\author{
Daniel Temp*
}

Resumo: O texto examina o modo como Nietzsche articula o elemento crítico de sua filosofia com as formulações éticas construtivas que ele defende. Seu objetivo é mostrar que as formulações positivas de Nietzsche guardam uma espécie de orientação normativa, ainda que em sentido mínimo. Dado que essa suposta orientação normativa deve manter coerência com suas críticas - e, portanto, deve ser distinta das concepções tradicionais que são criticadas -, começo identificando alguns compromissos elementares que o filósofo assume durante o empreendimento da crítica para em seguida elucidar a natureza e o estatuto da concepção de normatividade admitida por esses compromissos. Com isso chego a uma descrição em que embora qualquer juízo valorativo dependa de um elemento subjetivo básico, este é suficiente para assegurar sua força normativa. Ao final do texto sugiro uma possível caracterização da posição de Nietzsche como uma variante perfeccionista em que uma descrição formal dos valores como se definindo em relação à capacidade de conduzir à excelência está conjugada com a requisição de um tipo particular de confiança em si mesmo cuja função é conferir força normativa a esses valores.

Palavras-chave: valor - crítica - normatividade - perfeccionismo

* Doutorando pelo Programa de Pós-graduação em Filosofia da Universidade Federal de Santa Maria, Brasil. Correio eletrônico: daniel_temp_@hotmail.com 
Temp, D.

Kerêa: Sou como todos. Para me sentir livre desejo às vezes a morte dos que amo, cobiço as mulheres que as leis da família ou da amizade me impedem de cobiçar. Para ser lógico deveria então matar e possuir. Mas sei que essas ideias vagas não têm importância. Se todos se achassem com o direito de as realizar ninguém poderia viver nem ser feliz. E repito, é isso que me interessa.

Calígula: Acreditas então numa ideia superior.

Kerêa: Creio que certas ações são mais belas do que outras.

Calígula: Por mim, creio que todas se equivalem.

(Calígula, de Albert Camus).

I

A figura do imoralista é uma figura recorrente na história da filosofia moral. Em roupagem clássica, a encontramos representada nas personagens platônicas Cálicles e Trasímaco. Em várias ocasiões, porém, o termo ganha conotações niilistas: basta lembrar o significado do imoralismo representado por personagens de Sade. Não obstante a diferença entre a significação precisa de ambos os termos, niilistas e imoralistas costumam ser apontados juntos como negadores da moralidade. Quando isso ocorre, não são raras as vezes em que o nome de Nietzsche os acompanha. Assim, no excerto da peça que vai inscrito no princípio do texto, o imperador romano Calígula encarna a posição do imoralista que, segundo uma determinada vertente interpretativa, representa as consequências práticas niilistas da filosofia de Nietzsche ${ }^{1}$. Uma das principais características desse tipo de leitura é inferir que a partir das críticas aos pressupostos descritivos $^{2}$ que sustentam várias das reivindicações normativas

\footnotetext{
1 Como exemplo desse modo de leitura em que o imoralismo atribuído a Nietzsche corresponde a uma forma de niilismo, $c f$. Germano, 2013. De modo geral, a negação do imoralista é bem menos radical do que a de um niilista, uma vez que aquele nega os valores associados a perspectivas morais, enquanto este nega todos os valores. A despeito dessa diferença, no decorrer do texto utilizarei deliberadamente os termos imoralismo e niilismo de forma intercambiável, de modo que o primeiro terá por referência exclusivamente o imoralismo radical e indiferentista que algumas leituras atribuem ao filósofo, e não o significado preciso que o próprio Nietzsche atribui ao termo quando se autodenomina como imoralista.
}

2 No que se segue assumo essa distinção entre o componente descritivo e o componente normativo

94 | Cad. Nietzsche, Guarulhos/Porto Seguro, v.38, n.3, p. 93-123, setembro/dezembro, 2017. 
Nietzsche e a orientação perfeccionista de sua tentativa de estimar valores

as quais o filósofo se opõe, se segue que ele recuse o elemento normativo da filosofia prática como um todo. Com a crescente tendência naturalista em boa parte da filosofia contemporânea - e em especial na filosofia de língua inglesa - esse tipo de leitura tem sido reforçada. Dentre os que tendem a ler Nietzsche dessa forma a regra parece ser, por um lado, reaproveitar a força de várias das críticas a nível descritivo que ele formula contra seus adversários e, por outro, relegar a segundo plano o elemento normativo de sua filosofia, reduzindo-o a um amontoado de idiossincrasias.

Embora ainda existam leituras que enfatizem somente a dimensão crítica e negativa de sua filosofia, vários intérpretes reconhecem que Nietzsche também advoga um ideal valorativo positivo. Para que esse ideal faça sentido e não sucumba ao niilismo da radicalização de suas próprias críticas, é necessário esclarecer qual o status dessa normatividade reivindicada e como ele procede na defesa de seus valores. Levando em conta que ao longo de sua obra o filósofo faz diversos juízos de valor que partem dessa dimensão positiva de sua filosofia, afirmando, inclusive, que pretende avaliar o valor dos valores morais, temos o seguinte problema: qual o status das posições do próprio Nietzsche, visto que ao mesmo tempo em que ele as defende, a concepção que emerge de suas críticas supostamente nega a existência de valores objetivos ou com estatuto privilegiado? Em outras palavras: é difícil compreender sob que bases o filósofo defenderia suas próprias posições normativas frente a outras, isto é, como seria possível sua posição ética positiva usufruir de algum tipo de força normativa, visto que sua crítica inviabiliza qualquer justificação objetiva para ela.

\footnotetext{
da crítica de Nietzsche à moral. De modo geral, o componente descritivo se refere ao modo como seus oponentes concebem a agência humana: de acordo com Nietzsche, com base em uma série de pressupostos falsos. O componente normativo, por sua vez, diz respeito aos valores ou modos de vida favorecidos por seus opositores: aqui a crítica de Nietzsche não é formulada em termos de verdade ou falsidade de descrições, mas sim em termos do que se concebe como devendo ser buscado, isto é, sobre o que se crê ser mais valorável.
} 
Temp, D.

O texto que se segue trata da maneira como Nietzsche concilia o elemento negativo de sua crítica com a construção da dimensão positiva de seu pensamento. A tese fundamental que procuro defender alega que o próprio empreendimento da crítica à moralidade tem uma orientação normativa que funciona como seu fio condutor. Essa orientação normativa, no entanto, difere consideravelmente das concepções normativas tradicionais que são criticadas pelo filósofo. Para caracterizar com maior precisão qual a natureza dessa suposta orientação normativa presente na crítica de Nietzsche é necessário identificar quais são os compromissos elementares que tem um papel determinante no modo como ele concebe sua posição. Boa parte da discussão contemporânea a respeito desses compromissos se dá no terreno da metaética. Embora esses compromissos se assemelhem e possam encontrar paralelos em algumas posições metaéticas atuais, creio que seja improvável que eles possam ser inteiramente representados de forma adequada por elas. Desse modo, em vez de atribuir uma determinada posição metaética ao filósofo - o que implicaria atribuir a ele uma série de compromissos específicos bastante significativos que de modo algum são uma possibilidade clara no caso de Nietzsche - procurarei identificar alguns compromissos mínimos assumidos pelo filósofo, e, a partir deles, elencar algumas considerações que contribuem para uma formulação adequada do modo como ele entende o aspecto normativo da reflexão ética. Com isso espero fornecer os elementos básicos para uma leitura coerente em que a posição defendida por Nietzsche não apenas é formulada em consonância com suas críticas, mas também é o leitmotiv das mesmas.

Após formular uma possível explicação para o modo como Nietzsche articula sua descrição dos valores com o elemento normativo de sua filosofia, volto-me para as consequências práticas da concepção de normatividade admitida por sua descrição dos valores. De forma um tanto breve, sugiro que o sentido de normatividade que a posição

96 Cad. Nietzsche, Guarulhos/Porto Seguro, v.38, n.3, p. 93-123, setembro/dezembro, 2017. 
Nietzsche e a orientação perfeccionista de sua tentativa de estimar valores

de Nietzsche conserva não implica uma posição indiferentista onde todos os valores se equivalem (ao menos de um ponto de vista prático), mas, ao contrário, em sua essência sua posição visa combater a adesão arbitrária a perspectivas éticas, sendo que ela mesma tem boas razões em seu favor. Ao final, apresento um esboço do que poderia ser essa sua posição positiva, apontando a presença de traços perfeccionistas que ela contém.

\section{II}

Steven Hales nota uma característica peculiar nas investidas de Nietzsche contra as posições que ataca, e a descreve como "uma obliteração aparente de uma posição, seguida de um recuo para a abraçar parcialmente" (HALES, 1996). Hales não defende que Nietzsche seja um adepto fiel desse procedimento, mas o salienta como uma importante característica a ser observada quando se lê seus escritos, prevenindo assim que se confunda a força de suas investidas retóricas com a posição final que o filósofo sustenta. A posição que é o alvo primordial da crítica de Nietzsche é a interpretação metafísica (platônico/cristã) do mundo. Em registro descritivo, Nietzsche contrapõe a ela uma série de objeções em favor de uma interpretação do mundo deflacionada e naturalizada. Dentre essas acusações está a alegação da "morte de Deus", que, no fim das contas, tem por uma de suas principais consequências a ideia de que a natureza não contém valores nela mesma (FW/GC 301, 357, KSA 3.539, 597; JGB/BM 9, 108, KSA 5.21, 92). Posto que não existem como parte independente da realidade, valores são vistos agora como criações. A estratégia utilizada por Nietzsche consiste em rejeitar a interpretação metafísica que ataca apontando a falsidade, isto é, o caráter ficcional dos elementos da cultura humana, eliminando assim a "realidade extra" que esta nos faz postular acerca da natureza. Conforme a característica notada por Hales, ao mesmo tempo em que 
Temp, D.

dirige severas críticas a essa interpretação, por vezes o filósofo recua de seu ataque e volta a falar em cultura e valores, mas agora sem o compromisso com uma correspondência entre valores e natureza, mas sim entre valores criados e seus criadores. Ou seja, Nietzsche primeiro objeta contra a falsidade da interpretação metafísica, mas em seguida reconhece que a falsidade de um juízo não constitui uma objeção ao seu valor (JGB/BM 4, KSA 5.18; FW/GC 345, KSA 3.577). Tendo isso em vista, é possível perceber por que não há sentido em afirmar que se os valores não existem de forma objetiva, juízos de valor não podem usufruir de uma justificativa legítima: após as críticas do filósofo, a prática de justificar valores com base em sua existência objetiva está fora de questão, afinal agora são os próprios seres humanos que criam valores (em verdade sempre foram eles). Se antes algo era valioso porque se pensava que seu valor tinha existência objetiva, agora se reconhece que valores são palavras que se atribuem a determinadas coisas, pessoas, atitudes (M/A 210, KSA 3.189; Za/ZA I Da virtude dadivosa I, KSA 4.97). Nesse sentido, Nietzsche assume uma posição claramente antirrealista: ele defende que não existem valores objetivos, se com isso queremos designar sua existência como independente de criadores.

Todavia, considerando apenas os argumentos em registro descritivo, Nietzsche tem novamente diante de si a interpretação metafísica que procura repudiar. Se do ponto de vista descritivo ele tem a seu favor fortes críticas contra ela, ao admitir que o valor de algo é um assunto que independe da existência efetiva desse valor na natureza, o filósofo precisa de uma objeção a nível normativo para enfrentá-la, o que o obriga a assumir um compromisso básico com uma determinada perspectiva valorativa. Posto que os valores não existem independentemente de quem valora e por isso não é mais possível encontrar inscrita na natureza a existência objetiva dos valores - ou seja, do ponto de vista ontológico todos valores usufruem do mesmo status -, a perspectiva de Nietzsche carece de alguma fonte que lhe 
Nietzsche e a orientação perfeccionista de sua tentativa de estimar valores

forneça força normativa frente a outros tipos de valorações. A fim de obter alguma indicação sobre o modo como Nietzsche lida com essa questão, cabe atentar ainda para algumas características centrais que ele atribui aos valores ao se referir a eles. De modo geral, três principais características podem ser enumeradas:

a) valores são criados;

b) eles são relativos; e

c) não possuem autoridade normativa em si mesmos.

A primeira característica é uma consequência de seu "naturalismo". Se os valores não estão a priori no mundo, eles devem entrar nele através das pessoas. Em inúmeras passagens Nietzsche fala em termos de "atribuição", "doação" e até "empréstimo" de valores ao mundo. Como valores são criados é uma questão de que tratarei em seguida. Por ora basta enfatizar o caráter humano dos próprios valores, como atesta a seguinte passagem:

Valores foi o homem que primeiramente pôs nas coisas, para se conservar - foi o primeiro a criar sentido para as coisas, um sentido humano! Por isso ele se chama "homem", isto é, o estimador.

Estimar é criar: escutai isso, ó criadores! O próprio estimar é, de todas as coisas estimadas, o tesouro e a joia.

Apenas através do estimar existe valor: e sem o estimar seria oca a noz da existência. Escutai isso, ó criadores!

Mudança nos valores - isso é mudança nos criadores. (Za/ZA I Das mil metas e uma só meta, KSA 4.74)

A segunda característica nos traz novamente o problema da legitimidade dos valores defendidos por Nietzsche frente aos que critica. Se a existência de um valor depende de quem valora, a princípio inferimos daí que os valores são arbitrários. No entanto, o tipo de relação que Nietzsche tem em mente quando fala de valores 
Temp, D.

é menos uma relatividade radical $^{3}$ onde não haveria valores mais elevados que outros do que seu caráter relacional. O caráter relacional dos valores serve sobretudo para destacar que não existem valores "em si", absolutos, independentes de quem valora e com validade universal. Como não é mais possível colher os valores na realidade, as coisas são valoradas em função de algo, ou, em outras palavras, sua existência depende das características daquele que valora e são medidos em relação a determinada meta ou objetivo (que também depende de quem a postula - uma questão que será abordada a seguir, pois diz respeito diretamente à ideia de criar valores). Nietzsche ilustra o caráter relacional dos valores (no caso ele fala em virtudes) em um aforismo intitulado "A saúde da alma":

A apreciada fórmula de medicina moral (cujo autor é Ariston de Quios), "A virtude é a saúde da alma" - deveria ser modificada, para se tornar utilizável, ao menos assim: "Sua virtude é a saúde de sua alma". Pois não existe uma saúde em si, e todas as tentativas de definir tal coisa fracassaram miseravelmente. Depende do seu objetivo, do seu horizonte, de suas forças, de seus impulsos, seus erros e, sobretudo, dos ideais e fantasias de sua alma, determinar o que deve significar saúde também para seu corpo. (FW/GC 120, KSA 3.477).

O último aspecto enumerado diz respeito ao modo como determinados valores ganham autoridade normativa. O segundo aspecto alegava que algo é reconhecido como valioso em relação a determinadas características da pessoa que valora. No entanto, poucos são os que dão ouvidos às suas necessidades naturais mais

3 Nietzsche inclusive parece repudiar a derivação do relativismo vulgar a partir da inexistência de valores universais tanto quanto a derivação da universalidade irrestrita a partir da existência desses valores: "O erro habitual de suas hipóteses [dos historiadores da moral] consiste em afirmar um consenso dos povos, ao menos dos povos domesticados, a respeito de certos princípios morais, $e$ disso inferir a incondicional obrigatoriedade destes para cada um de nós; ou, inversamente, após compreenderem a verdade de que em diversos povos as avaliações morais são necessariamente diferentes, concluem pela não obrigatoriedade de toda moral: duas conclusões igualmente infantis." (FW/GC 345 , KSA, KSA 3.577).

$100 \mid$ Cad. Nietzsche, Guarulhos/Porto Seguro, v.38, n.3, p. 93-123, setembro/dezembro, 2017. 
Nietzsche e a orientação perfeccionista de sua tentativa de estimar valores

íntimas. Desse modo, Nietzsche explica o fato de muitas pessoas compartilharem valores de outros e os sentirem como obrigatórios através de uma descrição em que os valores de alguns raros indivíduos são impostos a outros mediante a força ( $c f$. FW/GC 39, KSA 3.406). Aqueles que foram submetidos aos valores dos mais fortes, entretanto, posteriormente acabaram por operar uma transvaloração - a conhecida "revolta dos escravos na moral" a que Nietzsche se refere diversas vezes em sua obra. Assim, a autoridade normativa ostentada pelos valores morais tradicionais é explicada através de um processo histórico-genealógico. Em verdade, Nietzsche dedica um livro inteiro - a Genealogia da Moral - para explicar esse processo em que a antiga imposição de valores que correspondem às condições optimais de certos estamentos sociais são "espiritualizados" e travestidos de uma autoridade quase intocável. Dessa forma, por negar a existência objetiva e universal de valores, Nietzsche nega também seu status normativo privilegiado. Se não há valores independentes de quem valora, não existem razões para alguém tomar como sua uma valoração estranha, a não ser que assuma os compromissos básicos dessa própria valoração, ou seja, o acolhimento de uma perspectiva valorativa qualquer reside, em última instância, na capacidade do agente reconhecer uma perspectiva como valorável - o que, por sua vez, depende de fatores sociais, culturais e, principalmente, de suas configurações psicológicas ${ }^{4}$. A título de exemplo: afirmar que não se deve mentir pois é errado não constitui uma razão para se agir de outro modo a não ser que já se compartilhe do pressuposto valorativo básico de que mentir é em si mesmo errado. A fim de mostrar que esse tipo de alegação constitui uma razão para agir de outro modo e

4 Cabe ressaltar: em última instância. A capacidade de acolher uma perspectiva não é sequer uma alternativa para muitas pessoas devido a limitações inatas ou de certa forma tão enraizadas que dificilmente seriam abandonadas. $O$ que importa notar é que, de acordo com a descrição em jogo, assumir um modo de valorar significa tomar para si (o que pode ocorrer de modo inconsciente) os pressupostos e conceitos básicos que constituem esse modo de valorar, estruturando a própria experiência a partir dessa perspectiva. Volto a essa questão na terceira e quarta parte deste texto.

Cad. Nietzsche, Guarulhos/Porto Seguro, v.38, n.3, p. 93-123, setembro/dezembro, 2017. | 101 
Temp, D.

seria irracional não lhe dar ouvidos, deveria ser possível demonstrar o porquê de mentir ser errado de forma irrestrita, o que, dada a tese nietzschiana de que os valores são criados e relativos, dificilmente seria possível. ${ }^{5}$

Essa caracterização do modo como os valores surgem é ela mesma parte da objeção descritiva que Nietzsche contrapõe às interpretações morais que ataca. Contudo, conforme dito anteriormente, essa não é a objeção cabal que Nietzsche formula contra a moralidade. A posição que Nietzsche sustenta não é preferível frente à concepção oposta unicamente porque esta se baseia em pressupostos falsos (embora isso possa aparecer como uma tentativa retórica de convencimento por parte do filósofo), mas sim porque Nietzsche pensa que sua posição tem mais valor do que a posição adversária. Aqui nos deparamos outra vez com o impasse entre a defesa de uma perspectiva valorativa e o compromisso com uma visão naturalizada de mundo onde não há valores objetivos. A tese de que gostaria de me valer é a seguinte: o modo como Nietzsche supera o impasse se dá por dois passos conjuntos; a partir de sua própria descrição - derivada de uma visão naturalista - que afirma que valores são criados, Nietzsche se compromete com uma perspectiva normativa na qual algo adquire valor com base em um critério que o próprio filósofo toma como tendo o mais alto valor: a excelência humana. Dito de uma maneira menos confusa: em um primeiro passo, a partir da descrição dos valores que ele mesmo fornece, Nietzsche reconhece que os valores são criações subjetivas, e ele - este é o segundo passo - enquanto criador, atribui a medida de valor à capacidade de tornarmo-nos melhores. A maioria dos intérpretes atuais reconhece que o núcleo da objeção de Nietzsche à moralidade se dá em um âmbito normativo, sendo feita a partir de uma perspectiva que o próprio filósofo assume: os valores morais que ele ataca são desprovidos de valor pois impedem o cultivo da

5 Essa descrição parece implicar a atribuição de uma posição atualmente chamada de internalismo de razões a Nietzsche. Para uma tentativa de leitura de Nietzsche como internalista, $c f$. Simon Robertson, 2011.

102 | Cad. Nietzsche, Guarulhos/Porto Seguro, v.38, n.3, p. 93-123, setembro/dezembro, 2017. 
Nietzsche e a orientação perfeccionista de sua tentativa de estimar valores

excelência humana. Trato de forma um pouco mais detalhada a noção de excelência na última seção. Por ora, basta sinalizar seu papel na formulação da posição normativa de Nietzsche.

O que importa notar, portanto, é que devido ao viés naturalista contido na filosofia de Nietzsche, sua descrição dos valores recusa a existência de uma dimensão normativa universal para estes, de modo que, no fim das contas, sua própria posição é como que metanormativa: ele defende ser valorável que os indivíduos encontrem eles mesmos os valores que os levem à excelência. Assumindo que o compromisso com esse pressuposto elementar é o que caracteriza a dimensão construtiva da filosofia de Nietzsche, é possível entender a alegação de que a falsidade de um juízo não constitui uma objeção ao seu valor, a saber, porque o valor de algo, para Nietzsche, se define em relação à capacidade que ele possui de conduzir o indivíduo à qualificação ou excelência, e isso independe da verdade das descrições que sustentam os valores. O próprio Nietzsche, por exemplo, reconhece grande valor em vários dos ensinamentos cristãos, a despeito dos erros descritivos que identifica neles. O que importa ressaltar é que ao assumir esse compromisso Nietzsche está em condições de, ele mesmo, encontrar os valores que lhe digam respeito e, assim, formular uma crítica normativa (em sentido fraco, não universal) à moral: ela é uma perspectiva decadente, desprovida de valor, pois suprime aquilo que para Nietzsche é a única atividade provida de algo como um valor intrínseco ${ }^{6}$, isto é, a própria capacidade de criar valores que conduzam à excelência. Assim, Nietzsche formula sua posição em consonância com sua própria descrição dos valores como criados, relativos (ou relacionais) e sem autoridade normativa externa.

6 Aqui o impasse torna-se patente: embora não admita a existência objetiva de valores, Nietzsche parece proceder como se houvesse valores com esse estatuto. Naturalmente a pergunta que se segue é: como isso é possível? Não obstante as soluções pareçam apontar em direção a teses antirrealistas, cabe mencionar que a teoria dos valores nietzschiana nega a existência de valores morais, de modo que a possibilidade de um tipo particular de realismo permanece aberta. A esse respeito, $c f$. Peter Railton, 2012.

Cad. Nietzsche, Guarulhos/Porto Seguro, v.38, n.3, p. 93-123, setembro/dezembro, 2017. | 103 
Temp, D.

III

Se entendemos a crítica de Nietzsche como parte de um projeto que vai da superação das concepções de moralidade tradicional até a defesa de um novo modo de valorar, tornam-se nítidos os dois movimentos que orientam a estratégia nietzschiana para realizar esse projeto: primeiro, a crítica à moral e aos seus pressupostos e, segundo, a partir do cenário que se desenha após essas críticas, a exortação de um novo modo de valorar. Tendo isso em vista, é possível compreender que embora após suas críticas Nietzsche flerte de perto com concepções imoralistas e niilistas, seu objetivo primordial é superá-las ${ }^{7}$. Resta saber se as consequências práticas de suas críticas permitem essa superação.

Conforme a descrição contida nas páginas precedentes, a posição defendida por Nietzsche não apresenta uma justificativa que a coloque como preferível em detrimento de outras posições, de modo que permanece a indagação: como Nietzsche procede na defesa de sua posição? Para responder a essa pergunta, cabe atentar ao que significa defender uma posição prática de acordo com a descrição de Nietzsche, isto é, tendo em vista a descrição de valores como nãoobjetivos e desprovidos de autoridade normativa universal. Já de início cabe salientar que a negação da existência objetiva de valores e de sua autoridade normativa tem por consequência imediata a recusa da noção fundacionista de uma justificativa última que legitime a moralidade como uma perspectiva incondicional, universal e provida de uma autoridade normativa que se sobreponha aos interesses e razões dos agentes, exigindo obediência independentemente desses interesses e razões (testemunho disso é a sombra do imoralista que paira sob qualquer sistema moral e pode simplesmente ignorar suas

7 Nesse sentido, Nietzsche é tão niilista quanto Descartes é um cético. Ambos os pensadores têm, respectivamente, niilismo e ceticismo como fases de suas filosofias, mas não como conclusão delas; antes pelo contrário, eles apenas se servem dessas posições com vistas a superá-las.

104 | Cad. Nietzsche, Guarulhos/Porto Seguro, v.38, n.3, p. 93-123, setembro/dezembro, 2017. 
Nietzsche e a orientação perfeccionista de sua tentativa de estimar valores

recomendações $)^{8}$. Se a atribuição dessa recusa a Nietzsche estiver correta, ele não apenas mantém uma posição cética bastante radical quanto à possibilidade de fundamentação última para qualquer perspectiva ética que prescreva valores, mas também se compromete com uma descrição inversa em que o engajamento prévio com os próprios valores prescritos constitui a justificativa de qualquer posição ética. Disso se depreende que é a atitude de estruturar a experiência de determinada maneira que define os valores com os quais alguém se compromete, ou seja, uma perspectiva valorativa reside, em última instância, em determinado modo de vida assumido pelo agente, e não o contrário (exemplo disso são as inúmeras vezes em que Nietzsche fala de valores como signos ou sintomas de algum tipo de vida $-c f$. FW/GC, Prefácio, 2, KSA 3.347; GD/CI, Os "Melhoradores" da Humanidade, I, KSA 6.98). O que se está designando aqui por modo de vida cumpre um papel central nessa descrição. O filósofo raramente utiliza o termo, mas recorro a ele como termo geral para designar - sem precisar decidir de forma cabal sobre a controversa questão acerca da liberdade da vontade - as determinações básicas sob as quais formamos e mantemos nossos valores. Por vezes Nietzsche se refere a sentimentos ou preconceitos herdados e localiza essa determinação a nível cultural (M/A 9, 16, 19, KSA 3.21, 29, 32). Em outras ocasiões ele parece reduzir os valores a sintomas que podem ter suas causas localizadas em elementos psicológicos ou mesmo fisiológicos (GM/GM, III, 15, 17, KSA 5.372, 77; GD/CI, "Os quatro grandes erros", I e II, KSA 6.88, 89). Se, por um lado, por "modo de vida" entendemos unicamente a mentalidade inerente a uma cultura, então evidentemente a posição de Nietzsche admite

\footnotetext{
8 Algumas leituras contemporâneas, e em especial as de vertente kantiana, negam que a recusa de um tipo robusto de realismo implique necessariamente em uma recusa do projeto de fundamentação da moral como uma perspectiva independente das inclinações dos agentes. Isso não chega a constituir um problema para a descrição que estou apresentando, pois embora não seja claro se essa descrição é, de fato, a mais adequada, ao menos parece ser claro que Nietzsche assume que ela seja e, desse modo, mantenha uma posição que o aproxime dos que atualmente são céticos quanto a possibilidade de fundamentação última para uma perspectiva moral.
}

Cad. Nietzsche, Guarulhos/Porto Seguro, v.38, n.3, p. 93-123, setembro/dezembro, 2017. | 105 
Temp, D.

uma espécie de relativismo cultural, tendo por objetivo substituir certas crenças e práticas por outras que julga superiores. Por outro lado, se entendemos "modo de vida" como se referindo ao modo de vida particular de um agente, a posição de Nietzsche está no limiar de um relativismo radical e nos defrontamos, outra vez, com a leitura imoralista. À primeira vista o relativismo parece incontornável e a posição normativa de Nietzsche, portanto, inócua.

O impasse pode ser resolvido se concedermos que levar determinado modo de vida significa estruturar a experiência de determinado modo. Isso, por sua vez, pode ocorrer de modo consciente ou inconsciente, e depende não apenas de uma série de fatores externos - e, portanto, tem algum apelo relativo à cultura - mas sobretudo de fatores internos, como as limitações e capacidades psicológicas próprias dos agentes envolvidos. Sendo assim, nesse contexto podemos entender "modo de vida" como designando algo semelhante à célebre noção de visão-de-mundo (Weltanschauung), isto é, o conjunto de crenças, sentimentos, impressões, capacidades e limitações psicológicas que configuram o modo primordial como um agente se relaciona com o mundo. $\mathrm{O}$ ponto em questão é que nas perspectivas morais tradicionais os agentes são levados a crer que aderiram a elas porque representam perspectivas com autoridade normativa objetiva - e, portanto, com privilégio normativo justificado sobre outras perspectivas -, quando, segundo a descrição nietzschiana, elas são defendidas e consideradas como perspectivas normativas privilegiadas apenas porque foram assumidas de antemão em seu modo de vida, ou seja, a partir de uma orientação subjetiva básica, e, desta forma, fazem parte do modo como eles estruturam sua experiência (na maior parte dos casos, inconscientemente).

Ao recusar uma fundamentação última para as perspectivas morais e deslocar a questão para o modo de vida ou a visão de mundo dos agentes, aparentemente Nietzsche está a prejudicar sua própria posição, na medida em que impede que ela seja objetivamente 
Nietzsche e a orientação perfeccionista de sua tentativa de estimar valores

preferível frente a outras. As leituras que tomam Nietzsche unicamente por imoralista (em uma acepção que reduz o termo a um significado similar ao que, no vocabulário de Nietzsche, denotaria muito mais o significado da palavra "niilista") partem dessa equivalência teórica entre as posições normativas para justificar a atribuição de um compromisso relativista ou subjetivista extremo ao filósofo. Entretanto, as consequências práticas de suas críticas, por radicais que sejam, não parecem levar necessariamente a essas concepções como conclusões de sua filosofia. As leituras que identificam em Nietzsche unicamente aspirações niilistas e iconoclastas parecem esquecer que o fato de não haver uma justificativa objetiva para a diferenciação teórica entre os valores não é uma justificativa objetiva para o imoralismo niilista - nem o poderia ser para nenhuma posição prática, sob pena de incorrer na gritante contradição de afirmar que o fato de não haver justificativas objetivas justifica objetivamente alguma posição ${ }^{9}$ - mas, ao contrário, é parte do projeto de Nietzsche que visa libertar os agentes da submissão a perspectivas morais para, em seguida, tornar possível a adesão à sua própria perspectiva, agora através de meios diferentes do que o apelo a uma autoridade normativa sustentada em concepções que ele considera equivocadas. Além disso, se considerarmos que a aproximação de posições mais radicais é apenas um primeiro passo de uma estratégia que visa a superação das posições concorrentes, o aspecto negativo da descrição nietzschiana tende a ser favorável à sua própria posição. Isso porque as formulações positivas que Nietzsche exorta, por serem formuladas em consonância com uma suposta descrição realista dos valores, evitam o compromisso com vários dos erros que ele identifica na moralidade.

Mais uma vez: se recusa os meios tradicionais, então como Nietzsche procede na defesa de sua posição? Mesmo admitindo as críticas de Nietzsche e reconhecendo que não existem justificativas

9 A esse respeito $c f$. os capítulos 1 a 3 de Bernard Williams, 2005.

Cad. Nietzsche, Guarulhos/Porto Seguro, v.38, n.3, p. 93-123, setembro/dezembro, 2017. | 107 
Temp, D.

objetivas, mas apenas determinações baseadas no modo de vida, por que alguém deveria abandonar sua visão de mundo e aderir à perspectiva que o filósofo advoga? Segundo a descrição de Nietzsche, o que ocorre é que quando um agente valora as coisas de determinado modo ele está a depositar confiança no valor de algumas ações. A confiança no valor objetivo de algumas ações em detrimento de outras, no entanto, é apenas confiança, e, portanto, tem caráter essencialmente subjetivo. Com isso não pretendo atribuir ao filósofo o compromisso com um tipo de subjetivismo que recusa de todo o apelo a razões práticas. $\mathrm{O}$ ponto em questão para a ideia de normatividade que sobrevive aqui é que mesmo essas razões deverão passar por uma espécie de inspeção subjetiva: mesmo que existam razões teóricas objetivas que sustentem algo, isso não significa que haja também razões práticas - isto é, razões que determinam o que se deve fazer - recomendando que se deva buscar ou se engajar com esse algo. A descrição naturalizada do mundo, por exemplo, pode ser aceita como uma descrição objetiva da realidade. Disso, entretanto, não se segue que tenhamos razões objetivas para nos comportar de modo a imitar a natureza. O fato de fumar fazer mal para a saúde é sustentado por uma série de razões objetivas. Disso, porém, não se segue que não devemos fumar. O máximo que se pode afirmar é que, caso queiramos ter saúde, devemos evitar o fumo. $\mathrm{O}$ aspecto normativo presente nesse tipo de descrição depende claramente de uma orientação subjetiva básica (que é fornecida pelo que chamei de "modo de vida" do agente), e, portanto, não tem caráter incondicional. Em contrapartida, ele não ignora por completo as informações objetivas relevantes para a questão. A situação que decorre da descrição de Nietzsche, creio, é semelhante. Compreendida assim, a estratégia de Nietzsche pode ser entendida como visando, em um primeiro momento, desmontar a visão de uma normatividade objetiva privilegiada por meio de uma descrição contrária em que o que há de normativo nos valores depende de elementos subjetivos, fazendo assim com que os agentes

108 Cad. Nietzsche, Guarulhos/Porto Seguro, v.38, n.3, p. 93-123, setembro/dezembro, 2017. 
Nietzsche e a orientação perfeccionista de sua tentativa de estimar valores

possam reconhecer o que há de arbitrário e externo sendo imposto em seu modo de valorar e, por consequência, em seu modo de vida. Isso para que, em um segundo momento, eles estejam em condições de alterar tanto seu modo de vida quanto suas valorações (ou, em léxico nietzschiano, transvalorar valores). Levando isso em conta, cabe explicar como a posição de Nietzsche é capaz de oferecer boas razões, mesmo que não derradeiras, para que se abandone as concepções morais tradicionais.

Acontece que a posição do filósofo compartilha um pressuposto elementar com a posição que ataca: ambos ainda são movidos pelo que Nietzsche denomina de "vontade de verdade". Este ímpeto, descrito pelo filósofo como "o conceito de veracidade entendido de modo sempre mais rigoroso, a sutileza confessional da consciência cristã, traduzida e sublimada em consciência científica, em asseio intelectual a qualquer preço" (FW/GC 357, KSA 3.597), tem origem em uma crença metafísica comum à mentalidade ocidental em geral, isto é, na crença do valor incondicional da verdade (FW/GC 344, KSA 3.574; GM/GM, III, 24, KSA 5.398). Do ponto de vista prático, essa crença acaba por tomar a forma de um juízo normativo que requer uma espécie de probidade intelectual frente a questões teóricas e práticas $^{10}$ (JGB/BM 227, 230, KSA 5.162, 167; M/A, Prólogo 4, KSA 3.15). Ocorre que, levada ao extremo, a probidade intelectual acaba por minar a si mesma: no fim das contas, ao mesmo tempo em que exige razões e justificativas para todo o tipo de crença, a exigência de probidade repousa ela mesma sobre uma mera crença, ou seja, em uma confiança no valor da verdade que, em última instância, resta injustificada. Levando isso em conta, ao trazer à consciência os erros descritivos que envolvem as perspectivas tradicionais a que Nietzsche se opõe, os agentes terão uma boa razão, mesmo que sustentada em um juízo de valor básico e subjetivo, para abandonar as perspectivas que envolvem esses erros, isso porque eles mesmos têm como orientação

10 A esse respeito, $c f$. P. van. Tongeren, 2012. pp. 170 -173.

Cad. Nietzsche, Guarulhos/Porto Seguro, v.38, n.3, p. 93-123, setembro/dezembro, 2017. | 109 
Temp, D.

normativa básica a ideia da probidade (embora dependente de um juízo de valor, e, portanto, ter caráter essencialmente subjetivo, por esse juízo ser um pressuposto valorativo comum tanto à perspectiva de Nietzsche quanto às perspectivas morais tradicionais, ambas as perspectivas reconhecerão a razão prática derivada desse juízo).

A partir dessas breves considerações já é possível ver como o filósofo pode mostrar para seus adversários que existem razões em favor do abandono da perspectiva moral tradicional em nome de uma descrição em que a própria atividade de fornecer razões não é mais vista como primordial, mas depende de uma orientação subjetiva básica. Mostrar como Nietzsche advoga sua posição nesse cenário é o próximo passo. Entretanto, por envolver uma caracterização mínima da posição do filósofo, isso será feito de forma parcial apenas na próxima seção. Antes disso gostaria de ilustrar, através de um exemplo tirado de Wittgenstein, no que consiste defender uma posição prática tendo em conta a descrição que decorre do abandono das concepções tradicionais de moralidade definidas em função da incondicionalidade de suas exigências e com validade universal, isto é, moralidade como uma instância provida de autoridade normativa privilegiada.

$\mathrm{Na}$ Conferência sobre Ética Wittgenstein descreve uma partida de tênis no intuito de ilustrar a distinção entre valores tomados em sentido relativo e valores tomados em sentido absoluto. Segundo Wittgenstein, ao advertir alguém que jogasse terrivelmente mal, este alguém poderia simplesmente replicar que sabe disso e não quer jogar melhor. No caso de alguém que dissesse uma mentira, no entanto, não poderíamos nos contentar com uma réplica semelhante à do jogador de tênis e afirmaríamos que a pessoa deve querer se comportar melhor. Enquanto no primeiro caso temos um juízo de valor relativo, no segundo temos um juízo de valor absoluto. Trazendo o exemplo para a discussão sobre Nietzsche, não é implausível identificar o filósofo como defendendo uma visão que nega a segunda situação (valores absolutos) em favor da primeira (valores relativos). Nesse

110 | Cad. Nietzsche, Guarulhos/Porto Seguro, v.38, n.3, p. 93-123, setembro/dezembro, 2017. 
Nietzsche e a orientação perfeccionista de sua tentativa de estimar valores

caso, ele defenderia que por não haver uma justificativa derradeira para a reivindicação de valores absolutos, não seria possível haver reivindicação normativa nenhuma, e, portanto, os valores seriam todos relativos. De acordo com o que procurei expor, porém, a recusa de uma justificação última ou a negação da existência objetiva de valores não acarreta a recusa da noção geral de normatividade, e isso porque Nietzsche concebe o problema de outro modo: uma vez que sua descrição dos valores afirma que eles são estimativas humanas que não existem por si só e que o valor de um juízo independe de sua verdade ou falsidade, a questão não é mais saber se nossas estimativas são verdades absolutas em que devemos crer, mas sim se temos razões em depositar confiança no valor de certas práticas, atitudes etc., sendo que Nietzsche admite que pode haver razões boas ou ruins, dependendo das aspirações do agente. Ou seja, diferentemente da dicotomia entre normatividade privilegiada e relativismo indiferentista implícita no exemplo de Wittgenstein, Nietzsche não vê a negação da existência de padrões absolutos como implicando a recusa da noção de normatividade como um todo, afinal mesmo não havendo uma justificativa objetiva última para a confiança em determinados valores, ainda assim ele concebe que podemos estar ou mais ou menos justificados em sustentar determinados valores. Sendo assim, mesmo a primeira situação descrita no exemplo conservaria um aspecto normativo mínimo, e seria possível manter a reivindicação normativa de que se crê que o jogador deve jogar melhor. Em casos como esse o que ocorre agora é que ao defender por que se deve (dever em sentido menos pretensioso do que uma deontologia universal) dar ouvidos a sua reivindicação, se está procurando fazer com que a pessoa a quem se busca convencer encontre algum motivo dentre os seus motivos e desejos que a faça ver as coisas de outro modo (ou seja, a origem da força normativa de uma posição depende sobretudo da motivação, e não da justificação; isso não significa, porém, o abandono da noção de justificação: caso a pessoa tenha ou encontre 
Temp, D.

algum motivo, ela terá uma justificativa para agir de outra maneira). De todo modo, assim como no exemplo de Wittgenstein acerca dos valores relativos, sempre é possível recusar a perspectiva que é oferecida. No fim das contas o modo como Nietzsche defende sua perspectiva de fato se assemelha com a primeira situação descrita por Wittgenstein: ao ver e avaliar que muitas vezes as pessoas perdem a si mesmas em nome de determinas concepções morais ou mesmo religiosas, Nietzsche oferece uma perspectiva alternativa. É como se ele dissesse, em analogia com o que é dito ao mau jogador de tênis: "você pode ser melhor que isso". Depende da própria pessoa advertida (e da capacidade de que ela dispõe para reconhecer algo como uma razão) avaliar a legitimidade e engajar-se na perspectiva de Nietzsche ou não, não havendo uma autoridade normativa que force a pessoa a deliberar pelo engajamento fora de seus próprios interesses e desejos. Não são poucas as vezes que o próprio Nietzsche adverte que a posição que defende certamente não é para todas as pessoas, e que algumas talvez nem sejam capazes de reconhecer seu valor. Isso, no entanto, não constitui um problema para sua posição. Não reconhecer valor em uma perspectiva que visa levar ao melhor de si mesmo é visto como um sintoma do tipo de vida que Nietzsche - a partir de sua própria perspectiva - considera inferior. Dado que Nietzsche não pretende operar com uma autoridade normativa que force os agentes a se engajarem em sua perspectiva, para aqueles que, reconhecendo que podem atingir um nível maior de excelência em relação a suas aptidões e capacidades, ainda assim preferem se conformar com o "eu não quero jogar melhor", o filósofo se limita a oferecer seu desprezo e alguns adjetivos providos de uma retórica pouco favorável.

112 | Cad. Nietzsche, Guarulhos/Porto Seguro, v.38, n.3, p. 93-123, setembro/dezembro, 2017. 
Nietzsche e a orientação perfeccionista de sua tentativa de estimar valores

IV

Até aqui me detive sobretudo no empreendimento crítico do projeto nietzschiano, o qual nos deixa em um cenário aparentemente desfavorável à defesa de uma posição normativa qualquer devido ao repúdio de noções como a de objetividade, universalidade e autoridade normativa. Entretanto, procurei mostrar também que, tendo em vista esse cenário, a possibilidade de qualquer ideia normativa passa a depender de um elemento subjetivo básico - o que significa, portanto, que ainda é possível conceber algum tipo de normatividade. $O$ ponto chave aqui é o fato de que agora - assumindo a inexistência de uma perspectiva com autoridade normativa sobre outras - as considerações relevantes para um agente pensar suas próprias valorações não partem de uma perspectiva objetiva que determina o que deve importar a ele independentemente de suas razões e motivos, mas, ao contrário, as considerações relevantes que determinam o que ele deve fazer partem exatamente de seus motivos e razões (no fim das contas, de sua visão de mundo ou "modo de vida" ${ }^{11}$. Em linguagem ordinária: a motivação para valorar alguma coisa qualquer em detrimento de outra não vem de fora do agente, mas sim de dentro. Esse deslocamento

11 Isso pode parecer uma petição de princípio: o que determina as "valorações" de um agente é seu "modo de vida" (entendido do modo como o defini, isto é, como o conjunto de configurações psicológicas e culturais que determinam o modo como um agente vê o mundo). No entanto, considerando que um dos objetivos da crítica de Nietzsche é mostrar, isto é, tornar consciente o papel dessa determinação (que outrora sequer era vista como determinação), uma vez tendo se dado conta do quanto seu modo de vida estava impregnado de valorações estranhas, um agente qualquer poderá livrar-se de parte dessa determinação, a saber, justamente aquela parte que estava operando inconscientemente sob a forma de uma aparente autoridade objetiva, e que agora é vista conscientemente como um erro. Ao livrar-se dessa determinação externa, o agente está em condições de reconhecer suas determinações mais básicas, isto é, determinações tanto psicológicas quanto fisiológicas que constituem o âmago do que ele realmente é ou de sua "vontade" (deixando de lado a questão a respeito da compatibilidade da determinação da vontade com a ideia de sua liberdade), e orientar-se em função delas. Sendo assim, a crítica de Nietzsche visa desmascarar as valorações com base em determinações externas (que, uma vez reconhecidas, muitas vezes são percebidas como arbitrárias e podem deixar de ser determinações), sem deixar de reconhecer o que há de determinante nas limitações e mecanismos internos do próprio agente. No fim das contas, é como se Nietzsche buscasse minar a determinação externa dos valores em nome de sua determinação interna.

Cad. Nietzsche, Guarulhos/Porto Seguro, v.38, n.3, p. 93-123, setembro/dezembro, 2017. $\mid \mathbf{1} \mathbf{3}$ 
Temp, D.

marca uma das principais diferenças entre a posição de Nietzsche e as concepções tradicionais, uma vez que a posição do filósofo passa a se fundar exatamente naquilo que move o agente a fazer algo, e não em interdições sobre o que ele não deve fazer. Uma vez tendo reconhecido o modo de valorar de que se valera até aqui como sendo arbitrário, ou, ao menos, como apoiado em uma ideia ilusória de objetividade, resta ao agente determinar a partir de si mesmo aquilo que importa a ele. A recusa da insistência em um modo ultrapassado de manter valorações em nome da apologia a uma busca por valores que tem início no próprio agente é um tema recorrente na filosofia de Nietzsche e é representado por máximas como: "O que diz a sua consciência? "Torne-se aquilo que você é" (FW/GC 270, KSA 3.519). Ou seja, é uma questão de consciência não mais apelar a instâncias que se sabe serem falsas, e assumir a responsabilidade de voltar-se a si mesmo na tentativa de encontrar valores. Tornar-se o que se é, nesse sentido, parece ser justamente reconhecer e deixar agir suas determinações mais íntimas e profundas que estavam cobertas de determinações estranhas e muitas vezes arbitrárias. Grande parte dos intérpretes atuais julga haver determinados traços nessas formulações positivas de Nietzsche que justificam sua aproximação com o que na história da filosofia tem se denominado de perfeccionismo moral ${ }^{12}$. No que se

120 perfeccionismo enquanto uma teoria moral tem sido caracterizado de diversas formas. Em uma de suas definições mais recorrentes ele é identificado com o desenvolvimento excelente da natureza humana. Algumas variações, porém, identificam o perfeccionismo com a realização de determinados bens objetivos (que podem ou não ser informados por uma descrição da natureza humana). Para uma série de definições, $c f$. Wall, Steven, "Perfectionism in Moral and Political Philosophy", The Stanford Encyclopedia of Philosophy (Winter 2012 Edition), Edward N. Zalta (ed.) (<http://plato.stanford.edu/archives/win2012/entries/perfectionism-moral/>). Há ainda uma tendência de caracterização contrária, na qual o perfeccionismo é menos uma teoria moral do que um dos aspectos essenciais da vida moral. De acordo com esse tipo de caracterização, o perfeccionismo diz respeito prioritariamente a uma relação de aprimoramento individual, isto é, trata-se de uma relação de aperfeiçoamento do indivíduo consigo mesmo (ou com seu eu ideal); sobre o perfeccionismo definido dessa maneira, $c f$. Stanley Cavell, 2005, p. 2. Na descrição que se segue no texto o perfeccionismo atribuído a Nietzsche se aproxima muito mais do segundo tipo de caracterização, muito embora seja bastante provável que o filósofo assuma alguns compromissos que permeiam outras definições e, dessa forma, desenvolva uma variante perfeccionista a seu modo.

114 | Cad. Nietzsche, Guarulhos/Porto Seguro, v.38, n.3, p. 93-123, setembro/dezembro, 2017. 
Nietzsche e a orientação perfeccionista de sua tentativa de estimar valores

segue, exponho alguns desses possíveis traços e busco mostrar que a formulação positiva de Nietzsche, não obstante mantenha afinidade com essas concepções, tenderia a se configurar como uma variante específica do perfeccionismo.

Na segunda parte do texto sugeri que o compromisso elementar da perspectiva de Nietzsche consiste na ideia que algo adquire valor em função de sua capacidade de conduzir à excelência. Essa caracterização do aspecto positivo de sua filosofia como voltada para a busca da excelência, contudo, permanece um tanto quanto imprecisa. Embora o filósofo pareça insistir na ideia de uma superação do estado de coisas no qual se encontra - o que já confere uma dimensão perfeccionista, mesmo que bastante ampla, à sua filosofia -, ele dificilmente oferece uma caracterização precisa do que seria essa superação. Assim, na Genealogia, Nietzsche afirma:

Mas de quando em quando me concedam - supondo que existam protetoras celestes, além do bem e do mal - uma visão, concedam-me apenas uma visão, de algo perfeito, inteiramente logrado, feliz, potente, triunfante, no qual ainda haja o que temer! De um homem que justifique o homem, de um acaso feliz do homem, complementar e redentor, em virtude do qual possamos manter a fé no homem! (GM/GM, I, 12, KSA 5.277).

A ideia implícita em passagens como essa parece ser a de que há um estado ou um modo de vida superior (isto é, com mais valor) do que o estado ou modo de vida atual e de que é possível atingi-lo (uma ideia parecida parece ecoar em FW/GC 288, KSA 3.528). Ora, esse estado é o que estou chamando de excelência. Com isso, porém, pouco foi acrescentado a uma caracterização substancial do que é a excelência, mas, pelo contrário, surge agora o problema de esclarecer em que sentido ela é um estado superior a outros. Por certo não há de ser em sentido objetivo, uma vez que as críticas de Nietzsche negam a existência de valores nesse sentido. É possível vislumbrar uma saída para o problema se repararmos que, segundo sua própria descrição, 
Temp, D.

Nietzsche afirma que os valores são criados (ou a confiança no valor de algo é depositada) em relação a necessidades e características naturais (e talvez também culturais) de seus criadores. Tendo isso em vista, uma vez livres da determinação externa de valores, cada qual estará em condições de encontrar um modo de articular valores da melhor maneira possível a partir de seu contexto de vida e suas possibilidades - o que significa, portanto, que o que conta como excelência tem uma dimensão subjetiva, se considerarmos que, em última instância, o próprio agente é quem julga qual seu conteúdo; isso não exclui, porém, a possibilidade do conteúdo da excelência depender também de alguns fatores objetivos, principalmente se considerarmos as determinações psicológicas mais originárias e as determinações fisiológicas que influem na vontade do agente; o ponto, enfim, é que a determinação do conteúdo da excelência está ligado necessariamente com o agente particular a que ela se refere. Assim, a noção de excelência humana pode ser entendida como uma noção prioritariamente formal que guia os indivíduos para que encontrem o que de melhor têm em si. É possível expressar a ideia em um raciocínio simples: ao perguntar qual é a melhor coisa que se pode ter na vida é digno de valor ao mesmo tempo tentar buscá-la, afinal buscar um bem menor do que o bem maior que se pode ter seria desprezível, característico de uma vida inferior ${ }^{13}$. Cabe deixar claro que o caráter formal dessa descrição não é sinônimo de caráter ideal $^{14}$, pois, conforme foi dito, ela engloba também a particularidade

13 A forma como apresentei o raciocínio é uma paráfrase de como Gavin Lawrence (2009, p. 42) descreve a concepção aristotélica de bem humano como objeto formal da racionalidade prática. É interessante notar que, resguardadas as diferenças, é justamente Aristóteles o filósofo mencionado junto a Nietzsche na ocasião em que John Rawls faz a primeira leitura que associa o nome deste a uma tradição perfeccionista.

14 Não é ideal no sentido de ser uma formulação utópica e inalcançável. Com relação a isso, o próprio Nietzsche adverte: "Não demais!" - Com que frequência o indivíduo é aconselhado a estabelecer para si uma meta que não pode atingir e que está além de suas forças, para atingir ao menos o que suas forças podem render na máxima tensão! Mas isso é realmente tão desejável? Os melhores homens vivem conforme esse ensinamento, e suas melhores ações, não adquirem algo de exagerado e contorcido, justamente porque neles há tensão demais? E uma cinzenta sombra de fracasso não

116 Cad. Nietzsche, Guarulhos/Porto Seguro, v.38, n.3, p. 93-123, setembro/dezembro, 2017. 
Nietzsche e a orientação perfeccionista de sua tentativa de estimar valores

do agente a que a excelência se refere, ou seja, o que conta como excelência para um indivíduo depende e se define em função das capacidades do próprio indivíduo. Nietzsche parece ter em mente algo semelhante quando afirma: “[...] mas tenho em boa conta as morais que me impelem a fazer algo e a refazê-lo, e sonhar com ele à noite e em nada pensar senão em fazê-lo bem, tão bem como somente eu posso fazê-lo!" (FW/GC 304, KSA 3.542). Sendo assim, a noção de excelência diz respeito a um estado que cada indivíduo possui e, caso livre de interferências externas, pode reconhecer como melhor, preferível, valorável. Nietzsche não define o conteúdo desse bem maior ou excelência pois ele varia de acordo com cada um e depende dos elementos que constituem seu ser de modo mais essencial. Aparentemente o que Nietzsche faz é sugerir algumas características gerais que devem orientar essa busca caso se assuma a sua perspectiva, isto é, caso se queira alcançar a excelência no sentido em que o filósofo propõe, que, no fim das contas, é o sentido que cada um (honesta e livremente) é capaz de dar a essa noção.

Tendo isso em vista, é possível identificar alguns "requisitos" da perspectiva advogada por Nietzsche: se considerarmos que o que ele chama de excelência é como que um estado superior de si mesmo, que valorar algo, a partir de sua descrição dos valores, é depositar confiança nesse algo, e que o compromisso básico de sua perspectiva requer que se assuma que a excelência e aquilo que conduz a ela é valorável, então segue-se que, na busca da excelência, é essencial depositar confiança em um estado superior de nós mesmos. Essa conclusão evidentemente depende da aceitação da última alegação, ou seja, sua força normativa depende da aceitação do compromisso básico de que a excelência tem o valor que se está atribuindo a ela e que, portanto, merece ser buscada. Dessa forma, o ponto em questão é que a adesão à posição de Nietzsche requer uma espécie singular de

se estende sobre o mundo, por vermos sempre atletas em luta, tremendos esforços, e nunca um vencedor coroado e contente da vitória? (M/A 559, KSA 3.325)

Cad. Nietzsche, Guarulhos/Porto Seguro, v.38, n.3, p. 93-123, setembro/dezembro, 2017. | 117 
Temp, D.

confiança que é bastante semelhante às noções de crença ou mesmo $f e ́$ familiares às antigas tradições religiosas: na adesão à perspectiva de Nietzsche o agente tem de aceitar como suficiente a justificação subjetiva de que dispõe (ao menos no que diz respeito a questões práticas) para tomá-la como uma perspectiva legítima em detrimento de outras. Nietzsche parece apontar essa relação entre a aceitação de uma crença básica e a busca disso que se crê valorável quando afirma: "E o que pode haver de mais belo que buscar suas próprias virtudes? Isto já não seria quase: crer em sua própria virtude?’" (JGB/ BM 214, KSA 5.151). Cumpre ressaltar, porém, que a noção de crença ou confiança com que Nietzsche opera conserva uma diferença fundamental em relação às antigas noções de crença ou fé no que concerne a seu objeto, pois a noção de fé da qual depende a busca da excelência na perspectiva nietzschiana tem como objeto exclusivo o próprio crente. Em outras palavras, a confiança requerida pelo suposto perfeccionismo de Nietzsche diz respeito exclusivamente a um estado elevado ou superior de si mesmo. Essa ideia pode ser vista em um aforismo que se chama justamente:

A fé em si mesmo. - Poucos tem fé em si mesmos: - e, desses poucos, alguns vêm com ela dotados, como uma útil cegueira ou obscurecimento parcial do espírito (o que não veriam, se pudessem olhar a si mesmos no fundo!), outros têm de conquistá-la: tudo o que fazem de bom, de apreciável, de grande, é primeiro um argumento contra o cético que neles habita: a questão é convencer ou persuadir este, e isso requer quase o gênio. São os grandes autoinsatisfeitos (FW/GC 284, KSA 3.527).

É interessante observar que apenas alguns trechos mais a frente, Nietzsche fecha um aforismo intitulado "Uma coisa é necessária" com as seguintes palavras:

Pois uma coisa é necessária: que o homem atinja a sua satisfação consigo seja mediante esta ou aquela criação e arte: apenas então é tolerável olhar para o ser humano! Quem consigo está insatisfeito, acha-se continuamente

118 Cad. Nietzsche, Guarulhos/Porto Seguro, v.38, n.3, p. 93-123, setembro/dezembro, 2017. 
disposto a se vingar por isso: nós, os outros, seremos as suas vítimas, ainda que tão só por termos de suportar sua feia visão [...] (FW/GC 290, KSA 3.530)

Ora, se Nietzsche crê ser necessário estar satisfeito consigo e ao mesmo tempo afirma, algumas páginas antes, que os grandes insatisfeitos são os que não têm fé em si mesmos, depreende-se daí que ele também crê ser necessário, a fim de satisfazer-se, que se tenha fé em si mesmo. Ainda em favor de uma leitura em que a confiança em si mesmo aparece como uma característica elementar da posição que advoga, Nietzsche expressa:

Não são as obras, é a fé que aqui decide, que aqui estabelece a hierarquia, para retomar uma velha fórmula religiosa num sentido novo e mais profundo; alguma certeza fundamental que a alma nobre tem a respeito de si, algo que não se pode buscar, nem achar, e talvez tampouco perder. A alma nobre tem reverência por si mesma." (JGB/BM 287, KSA 5.232)

A partir desses elementos já se pode entrever a configuração de uma estrutura mínima para a posição do filósofo: sua posição se caracteriza por ser uma espécie de perfeccionismo que apela diretamente ao agente, exortando-o a empreender uma busca por aquilo que ele genuinamente é. Nietzsche estima esse suposto estado como sendo o que de mais valorável um indivíduo pode atingir, isto é, como sendo sua excelência. Essa busca, no entanto, depende de um elemento de cunho primordialmente subjetivo como seu motor $^{15}$. Embora necessite de uma caracterização um pouco mais

15 Algumas definições do perfeccionismo afirmam que um de seus principais aspectos consiste na alegação psicológica de que desenvolver ao máximo seu potencial, cultivar suas capacidades naturais, enfim, elevar-se a excelência é o que cada um mais profundamente quer $(c f$. Thomas Hurka, 2001, p. 1289). Da maneira como a estou caracterizando, a posição de Nietzsche não compartilha desse otimismo teórico. Em vez de constatação psicológica de que cada um tende a querer desenvolver a excelência, creio que Nietzsche está comprometido com a visão de que cada um deve desenvolver o que mais genuinamente quer a fim de alcançar sua realização ou excelência. Ao contrário da primeira alegação, que tinha caráter descritivo, a segunda alegação (que estou atribuindo a Nietzsche) passa a ser normativa. Uma vez que a ideia de normatividade com a qual 
Temp, D.

substancial, procurei mostrar que esse elemento é a fé ou confiança em si mesmo. A ideia geral de fé em si mesmo surge como uma característica fundamental e necessária para a adesão à perspectiva de Nietzsche, pois é ela, enquanto crença subjetiva básica, que lhe confere força normativa ( $c f$. nota 15). Deste modo, é a noção de fé em si mesmo que permite explicar, de forma coerente com a descrição dos valores que Nietzsche fornece, como ele procede na defesa de seus valores em detrimento de outros. Além disso, essa confiança ainda é requerida a fim de que o comportamento exortado pela perspectiva de Nietzsche seja, de fato, a busca pela excelência (tal como ele a entende, ou seja, uma busca que se dá a partir de si mesmo) e não o disfarce para a satisfação de outras necessidades nem tão nobres e nem tão autênticas. Assim, essa crença ou confiança em um estado de realização mais pleno de si mesmo não constitui uma crença em um ideal externo que o indivíduo persegue, mas, ao contrário, é uma confiança fundamental que estrutura a experiência e a visão de mundo dos indivíduos, e cuja origem e cultivo se dão em consonância com suas determinações e limitações próprias.

Com esse pequeno esboço do que poderia ser a formulação positiva de Nietzsche, espero ao menos ter mostrado que o filósofo não se rende ao niilismo ou imoralismo radical decorrentes de suas críticas, mas, ao invés disso, procura reorientar o modo como os indivíduos concebem suas valorações e sua visão de mundo de acordo com o cenário que surge após as críticas. Procurei mostrar também que o elemento subjetivo básico do qual passa a depender qualquer tipo de valoração é suficiente para que um agente possa estimar valores hierarquicamente, e, portanto, não implica necessariamente em imoralismo em sentido radical ou niilismo

Nietzsche opera se funda em um elemento subjetivo, a adesão à sua própria posição depende de um elemento subjetivo que caracterizei como uma espécie de confiança em si mesmo: a confiança de que suas próprias necessidades, interesses e desejos, caso cultivados, levem ao melhor. Em outras palavras, confiança de que dar ouvidos às suas próprias necessidades e interesses mais íntimos é o que há de mais valorável.

120 | Cad. Nietzsche, Guarulhos/Porto Seguro, v.38, n.3, p. 93-123, setembro/dezembro, 2017. 
Nietzsche e a orientação perfeccionista de sua tentativa de estimar valores

(ainda mais se considerarmos os interesses e necessidades subjetivas compartilhadas por agentes). De qualquer forma, Nietzsche não parece se intimidar com posições niilistas, antes pelo contrário, as enfrenta na expectativa de superá-las. Para tanto, sugeri que ele formula uma variante perfeccionista que convida o agente a determinar suas próprias valorações e a si mesmo. A confiança ou fé em si mesmo que constitui o elemento subjetivo sobre o qual repousa a fonte normativa da perspectiva nietzschiana foi caracterizada apenas de modo inicial, e, portanto, carece de complementações: a ideia de crença deve ser desenvolvida de modo a esclarecer seu papel e estatuto psicológico, pois Nietzsche visivelmente repudia os objetos da crença oriunda de tradições religiosas ( $c f$. FW/GC 347, KSA 3.581); se isso faz com que ele rejeite as noções gerais de crença ou fé como um elemento relevante para suas formulações positivas é outra questão. Ademais, deve-se esclarecer sua relação com o pensamento do eterno retorno, que por certo tem papel crucial na determinação da força normativa de um modo de valorar. Estas, porém, são questões que escapam aos propósitos deste texto. Por fim, cabe ressaltar ainda uma última vez que no que diz respeito ao propósito geral do que foi exposto, trata-se fundamentalmente de ver a posição de Nietzsche de outro modo: ela é formulada como uma orientação normativa que não se confunde necessariamente com posições niilistas; o excerto da peça com que iniciei o texto pode ilustrar essa modificação no modo de ver as coisas: não obstante tradicionalmente se associe o filósofo a figuras niilistas e, dessa forma, seja tentador vê-lo representado por Calígula, de acordo com o que procurei expor sua posição seria melhor representada pela postura de Kerêa, que diz: "creio que algumas ações são mais belas do que outras". Ou seja, a confiança depositada no valor de algumas ações (casualmente expressa em termos pelos quais Nietzsche também tem a mais alta estima, isto é, em termos estéticos) é suficiente para livrá-lo do niilismo indiferentista e orientá-lo nos 
Temp, D.

caminhos que conduzem e formam a sua vida de acordo com aquilo que ele, com boa consciência, julga ser o melhor.

Nietzsche and perfeccionist orientations of his attempt to estimate values

Abstract: The text examines how Nietzsche conflates the critical element of his philosophy with the constructive ethical formulations that he advocates. His aim is to show that Nietzsche's positive formulations retain a kind of normative guidance, even though in a minimal sense. Given that this supposed normative guidance must maintain coherence with his critique - and therefore must be distinct of the traditional conceptions which are criticized -, I start by identifying some elementary commitment that the philosopher assumes at the time of his critique in order to clarify the nature and the status of the conception of normativity that these commitments admits. Thereby I arrive at a description where although any evaluative judgment rests on a basic subjective element, this element is enough to ensure his normative force. At the end of text, I suggest one possible characterization of Nietzsche's position as a variation of perfectionism where a formal description of values that are defined regarding his capacity of promoting excellence is conjugated with a requisition of a particular type of self-reliance, whose function is to grant normative force to these values.

Key words: value - criticism - normativity - perfectionism

\section{Referências bibliográficas}

BECKER, Lawrence C.; BECKER, Charlotte B. Encyclopedia of Ethics, New York: Routledge, 2001.

GERMANO, Emanuel. Combate ao niilismo e ao totalitarismo em Camus: um contraponto teatral e filosófico às concepções lúdicas e estéticas da existência. Revista Criação \& Crítica, n. 10, 2013, pp. 23-37.

HALES, S. D. Nietzsche sobre a lógica. Tradução de Desidério Murcho. In: Philosophy and Phenomenological Research, Vol. LVI, N. ${ }^{\circ} 4$, Dezembro 1996, pp. 819-835. Disponível em: <http://criticanarede.com/nietzlogica.html> Acesso em Julho de 2016.

HURKA, Thomas. Perfectionism. In: Encyclopedia of Ethics, ed. Lawrence C. Becker and Charlotte B. Becker. New York: Routledge, 2001.

122 | Cad. Nietzsche, Guarulhos/Porto Seguro, v.38, n.3, p. 93-123, setembro/dezembro, 2017. 
Nietzsche e a orientação perfeccionista de sua tentativa de estimar valores

LAWRENCE, Gavin. O bem humano e a função humana. In: Richard Kraut. (Org.). Aristóteles: a ética a Nicômaco. Tradução de Alfredo Storck. Porto Alegre: Artmed, 2009.

NIETZSCHE, Friedrich. Sämtliche Werke. Kritische Studienausgabe (KSA), 15 vols. (Organizada por Giorgio Colli e Mazzino Montinari), Berlim: Walter de Gruyter \& Co., 1988.

. A Gaia Ciência. Trad. Paulo César de Souza. São Paulo: Companhia das Letras, 2001.

Aurora. Trad. Paulo César de Souza. São Paulo: Companhia das Letras, 2004.

. Além do bem e do mal. Trad. Paulo César de Souza. São Paulo: Companhia das Letras, 2005.

. Assim falou Zaratustra. Trad. Paulo César de Souza. São Paulo: Companhia das Letras, 2011.

. Genealogia da moral. Trad. Paulo César de Souza. São Paulo: Companhia das Letras, 2009.

. Crepúsculo dos Ídolos. Trad. Paulo César de Souza. São Paulo: Companhia das Letras, 2006.

RAILTON, Peter. Nietzsche's Normative Theory? The Art and Skill of Living Well. In: JANAWAY, Christopher \& ROBERTSON, Simon. Nietzsche, Naturalism and Normativity. Oxford: OUP, 2012, pp. 20-51

ROBERTSON, Simon. Normativity for nietzschean free spirits. Inquiry: An International Journal of Philosophy, 54:6. 2011, pp. 591-613.

TONGEREN, P. van. A moral da crítica de Nietzsche a moral: estudo sobre Para além do bem e do mal. Trad. Jorge Luiz Viesenteiner. Curitiba, PR: Champagnat, 2012.

WILLIAMS, Bernard. Moral: uma introdução à ética. Tradução de Remo Mannarino Filho. São Paulo: Martins Fontes, 2005.

Artigo recebido para publicação em 07/04/2017 Artigo aceito para publicação em 30/07/2017

Cad. Nietzsche, Guarulhos/Porto Seguro, v.38, n.3, p. 93-123, setembro/dezembro, 2017. | 123 